\title{
SOBRE UM CASO DE SINDROME HISTERICA COM PARAPLEGIA FLACIDA E ASTASIA- ABASIA TIPO PARETICO (*)
}

\author{
DR. J. LAMARTINE DE ASSIS
}

J. A. S. - Soldado - Casado - Com 26 anos - Alagoano.

\section{ANAMNESE}

História da moléstia atual: Sua moléstia atual iniciou-se ha 6 mêses, após uma grande emoção e abalo físico: conta-nos que estava à cavalo em instrução, quando sofreu um coice de outro animal, caindo então numa poça dagua; perdeu os sentidos e só acordou numa enfermária do H. M. Não sofreu, do ponto de vista físico, senão um ferimento leve no terço médio da perna direita. Tentando andar por essa ocasião, não conseguiu faze-lo senão com auxilio de muletas, porem essa fase logo passou e o paciente diz ter andado muito bem, depois. Contudo, nem tudo estava normal nos membros. inferiores, por isso que o doente começou a sentir dormencia (sic), a princípio na perna direita, depois coxa do mesmo lado, para finalmente, de modo descendente atingir a coxa, perna e pé do membro opôsto. Disse-nos então, que as suas pernas fcaram esquecidas, (sic) a marcha foi-se-lhe tornando dificil obrigando-o a baixar novamente o hospital. Desde a ocasião do acidente acima referido, diz o paciente que vem tendo muitos ataques cujos casacteristicos são descritos por ele do seguinte modo: - o ataque surge quasi sempre após uma grande emoção, ou contrariedade, iniciando-se com palpitações violentas e sensação de calor no rosto; os dedos vão-se tornando rijos e em garra, e as pernas começam a tremer; em seguida a vista escurece e o paciente cae. Durante o ataque não há perda completa dos sentidos porquanto o doente percebe vagamente o que se passa ao seu redor. Nunca urinou, defecuo ou mordeu a lingua durante o acesso. Tem-se machucado lévemente nas quedas, mas estas, quasi nunca são bruscas. Após o ataque fica transitóriamente amnésico.

Anicccdentcs familiares: Em relação aos antecedentes familiares nada de interesse a não ser o fato de não existirem moléstias nervosas ou mentais, nem afecções infecto-contágiosas graves na familia e ancestrais ou colaterais.

Antecedentes pessôais: $\mathrm{O}$ paciente é tabagista moderado; nunca foi $\mathrm{e}$ 1:ão é etilista. E nascido de parto a termo e que foi normal. Das moléstias comuns na infancia só conta varicela. Nega moléstias infecto-contagiosas graves anteriores, acidentes ou operações cirúrgicas. Nega antecedentes venereo-sifiliticos. Jada conseguimos apurar em relação a qualquer outra intoxicação ou infecção.

Exame físico geral: Este exame nos mostra um individuo do "grupo longelineo" (classificação Barbara-Berardinelli), mal nutrido e com mucosas

(*) Trabalho apresentado e discutido na Sociedade Médica São Lucas. 
visiveis descoradas ligeiramente. Não há estigmas luéticos. Emotividade facil, disturbios vaso-motores nítidos, dermografismo, e cianose das extremidades, onde se nota um tremor curto e rápido. Discreta atrofia dos músculos dos membros inferiores. Não encontramos qualquer foco de infecção.

Exame físico especial: Nada nos revelou de anormal.

\section{EXAME NEUROLOGICO}

1 - Motricidade: a) voluntária: O paciente apresenta paralisia dos membros inferiores, sem nenhum sinal de síndrose deficitária piramidal. A força múscular se apresenta ligeiramente diminuida nos membros inferiores. Ausencia de incoordenação, seja sensitiva seja cerebrar, para os membros superiores, e prejudicada na sua pesquiza para os membros inferiores.

b) movimentação passiva: Normal, excepto o tonus que se apresenta discretamente diminuido dos membros inferiores.

c) automática: toda normal excepto a marcha, pois o doente para ficar em pé faz esforço e alarga sua base de sustentação enquanto que seu andar é feito com passos hesitantes, incertos, sendo que o paciente como que tenta com os braços tomar apoio no ar para não perder o equilibrio; antes de iniciar a marcha o doente parece refletir um pouco, como que a estudar os primeiros passos e tomar o impulso necessário. Olhos fitos no chão. $\mathrm{O}$ tronco vae oscilando um pouco durante a marcha. $O$ doente em absoluto não consegue voltar-se rápidamente

d) involuntária: na expontanea observa-se tremores nos membros inferiores, tremores esses que muitas vezes constituem os prodromos de proximos ataques, e que se observam também nas extremidades dos membros superiores. Os espasmos das mãos com flexão do dedos formando garras, são vistos somente durante os acessos.

Quanto aos reflexos apresentam-se todos normais, ausencia do sinal de Babinski e equivalentes, não havendo clonus nem automatismos ou sincenesias.

$2 \rightarrow$ Sensibilidades: Parestesias nos membros inferiores. Anestesia completa tactil termica e dolorosa nos membros inferiores, por ocasião do primeiro exame. Todas as outras sensibilidades apresentam-se absolutamente normais. Por ocasião da $1 .^{\text {a }}$ seção de torpillage desapareceu a anestesia que reapareceu algumas semanas depois.

3 - Discreta atrofia dos músculos das pernas, dermografismo e cianóse ligeira das extremidades. Não ha e nunca houve disturbios esfincterianos.

Exame psíquico sumatrio: Trata-se de um individuo de cultura inferio, inteligencia mediocre, muito sugestionavel e com desequilibrio das reaşues vaso-motoras e secretoras muito nitido no rosto; tem tendencia aos espasmos e tremores consoante resalta do seu exame neurologico; é muito sugeito it ataques cujos caracteristicos já foram descritos na anamnése. Reage intensamente às emoções saindo abrutamente do seu estado habitual de timidez - é hiperemotivo por excelencia. Após emoşoes ou contrariculades ou mesmo choques físicos, agravan-se os disturbios já referidos, culminando cim - ataque. Está muito bem orientado tanto atto como alopsinucamente. nunca apresentou ideias delirantes nen disturbios de percepcĩn. A pris.... ataques apresenta-se amnésico, sucedendo-se um ligeiro estario de sumbentia. sem nenhuma agitação ou delirio. Pela prova la hiperpneia ou somente jecla 
sugestão o paciente tem o ataque que obedece a todas as caracteristicas já descritas.

\section{SINTESE SEMIÓTICA}

Trata-se de um paciente que, há 6 mêses, após uma forte emoção e abalo físico começou a apresentar disturbios acentuados na deambulação, parestesias nos membros inferiores cujos segmentos tiveram seus movimentos ativos abolidos, e pequenos ataques de natureza indiscutivelmente pitiatica.

Os antecedentes nada revelam de importancia para o caso a não ser fatos negativos. O cxame físico dos orgãos e aparelhos nada revelou de anormal.

O exame ncurológico mostrou uma paraplegia flácida com díscreta atrofia dos músculos da perna, astasia-abasia (de tipo paralitico), tremores nos membros inferiores que aparecem expontaneamente ou pela sugestão, qualquer que seja a posição do doente, e que frequentemente constituem o sinal premonitorio do ataque. Os espasmos com flexão dos dedos das mãos só observamos durante o accsso. Parestesias com anestesia total nos membros inferiores por ocasião do primeiro exame. Nada encontramos que afirmasse lesão nervósa central ou perifćrica. Todos os exames complementares, inclusive o exame completo de líquido céfalo-raquidiano feito pelo Dr. Jarbas Veiga de Barros na Assistencia Geral dos Psicopatas, e o exame eletrico dos nervos e músculos dos membros inferiores feito por nós no $H$. M., nada revelaram que indicasse lesão nervosa central ou periferica; o eletrodiagnostico revelou apenas uma hiperexcitabilıdade galvanica que explicamos pelas dóses de estricnina que o doente vinha usando até o dia do exame.

Finalmente o exame psiquico mostrou-nos um paciente hiperemotivo, muito sugestionavel e com intensas alterações vaso-motoras e secretoras maximé no rosto. Todas as perturbações descritas agravam-se com as emoções e choques físicos, culminando com o ataque. Este foi obtido sempre em menos de 4' com a prova da hiperpneia, e frequentemente pela simples ação psiquica.

\section{EXAMES COMPLEMENTARES}

1 - Khan: negativo.

2 - Urina: nada de anormal.

3 - Radiografia dos pulmões: campos pulmonares de aspecto normal.

4 - Neuro-ocular: normal.

5 - Exame do líquido céfalo-raquidiano:

Punção SOD - liquor limpido, incolor e sem deposito.

Pandy - Nonne - e Weichlerotd - negativas.

Benjoin: 00000.00000 .00000 .

Ouro: 000.000 .000 .0 .

Wassermann: neg. com $1 \mathrm{cc}$.

Takata-Ara: nega.

Albumina e citologia: normais.

a) Dr. Jarbas $V$ de Barros. 


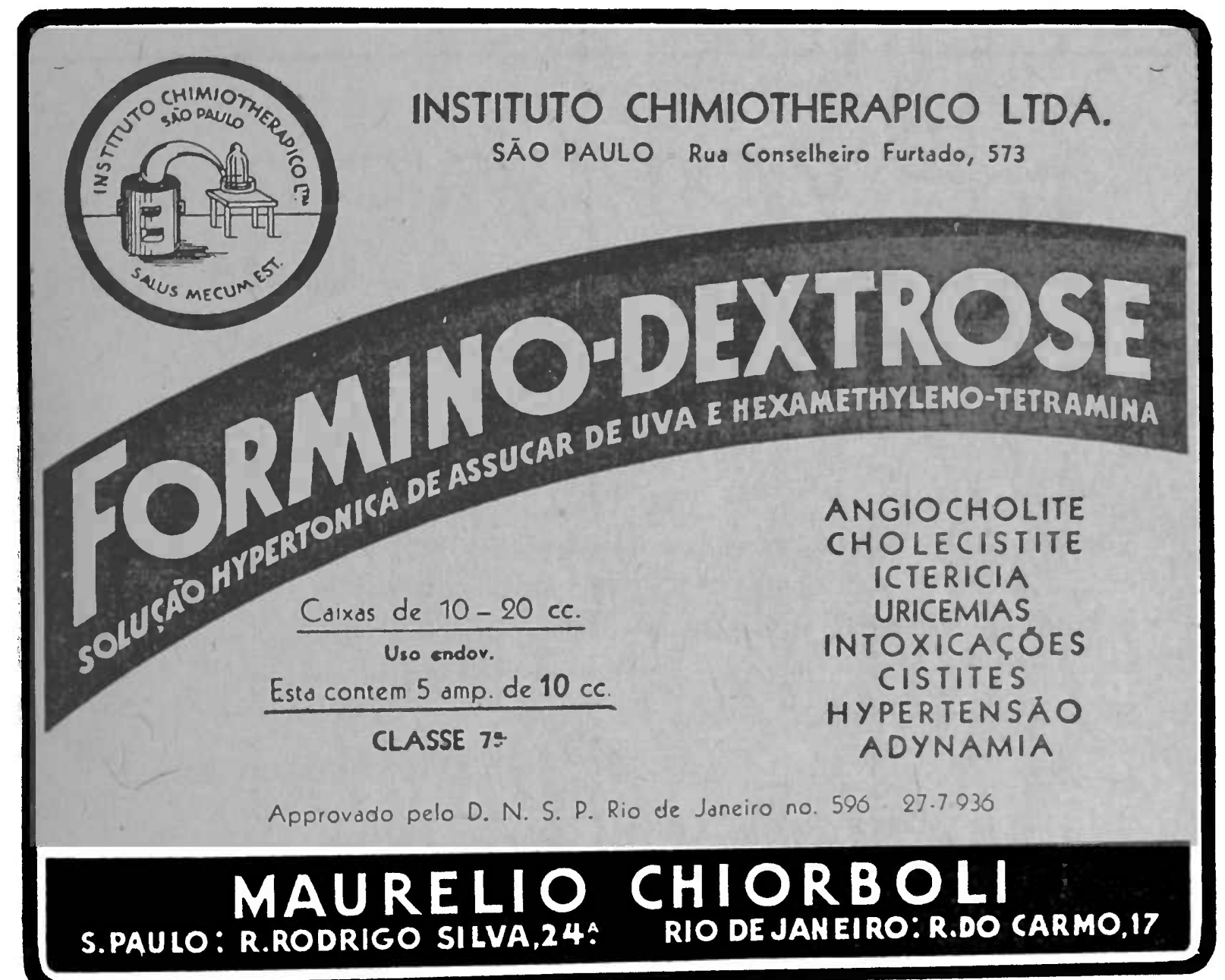




\section{F A B R I C A "NERO"}

RUA DR. SERgIO MEIRA N.o 199 - PHONE 5.2947 - SÃO PAULO

Artigos para copa, cosinha e banheiros esmaltados em todas as cores - Armarios hygienicos - Tampas para latrinas - Espelhos com xassis de madeira - Bancos para banheiros - Moveis esmaltados de madeira: mezas, cadeiras, armarios bufet - Des. pensas, geladeiras \&c.

ARTIGOS PARA TOdOS OS PREÇOS - VENDAS A VISTA E A PRAZO.

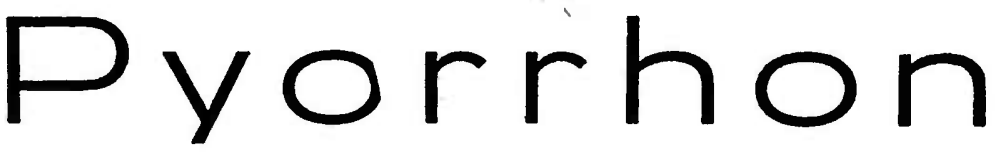

Um medicamento que veio resolver os casos de Gengivites e Piorréa

\section{ATESTADO}

E' para mim um prazer atestar que venho empregando em minha clinica com os mais brilhantes resultados, o PYORRHON, medicamento de escol para o tratnmento da Piorréa Alveolar e das Gengivites.

Tambem venho calorosamente recomendando o seu uso aos meus pacientes, porque assim fazendo estes teem assegurada a perfeita saude do seu meio bucal.

O PYORRHON é um preparado que pela propaganda honesta com que é lan. sado e pelos seus meritos, merece da nossa classe a melhor acolhida.

São Paulo, 6 de Outubro de 1939.

OCTAVIO DEMACQ ROSAS.

Receite PYORRHON aos seus clientes

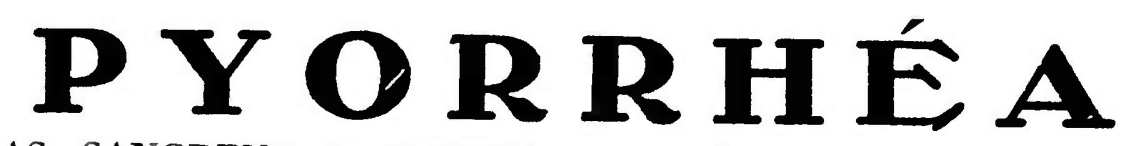

GENGIVAS SANGRENTAS, DENTES ABALADOS E MAU HALITO: RESUL:

TADOS POSITIVOS EM 8 DIAS, COM O ESPECIFICO PYORRHON.

C O N S U L T A S: $\quad 20 \$ 000$

Demonstrações praticas aos senhores medicos e dentistas.

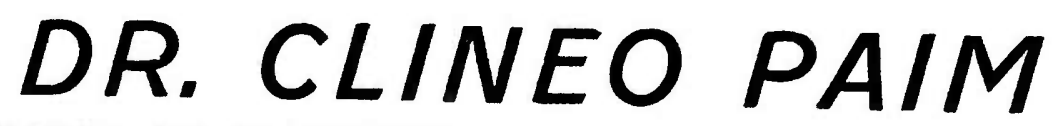

RLA BARÃO DE ITAPETININGA, 120 - 4. $0^{\circ}$ ANDAR - SALA 409

TELEPHONE. 4-4050

(Casa Guatapará) 
6-Exame elétrico: de J. A. S.

direito esquerdo

Nervo ciatico popl. externo ....................

Musculo tibial anterior ........................

Musculo peroneo lateral longo .................

Musc. extensor comum artelhos $\ldots \ldots \ldots \ldots \ldots \ldots$

$" \Rightarrow$ prop. do grande art. $\ldots \ldots \ldots \ldots \ldots$

Musculos gemeos ............................

Musculo quadriceps. . .........................

$\begin{array}{ll}1 & 1 \\ 4,5 & 3 \\ 2,8 & 3 \\ 5 & 4,5 \\ 3,8 & 4 \\ 3 & 3 \\ 3 & 3 \\ 2 & 5 \\ 2,8 & 2 \\ 1 & 1 \\ 4 & 4\end{array}$

Musculos gluteos ..........................

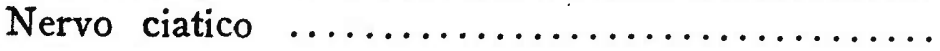

Hiperexcitabilidade galvanica dos nervos e musculos.

a) Dr. Lamartine de Assis. paretica.

Diagnostico: Sindrome histerica com paraplegia flacida e astasia-abasia

\section{DIAGNOSTICO DIFERENCIAL}

Em primeiro lugar eliminamos as lesōes nervosas centrais pela ausencia de sinais e sintomas de libertação ou de sindrome deficitaria piramidal, e de disturbios esfincterianos e genitais; a atrofia muscular bem assim como a hipotonia existentes nos músculos dos membros inferiores decorrem da inatividade mais ou menos prolongada destes. Além disso acresce a negatividade absoluta do líquido céfalo-raquidiano. Eliminamos as lesões do neuronio motor periférico pela presença de reflexos patelares e aquilianos normais durante todo o tempo em que controlamos o paciente; ausencia de dores nos territorios nervosos periféricos, sejam expontaneas sejam provocadas; anestesia total e fugaz nos dois membros inferiores, com conservação de todas as sensibilidades profundas, o que só pode falar contra qualquer lesão do neuronio periférico, por isso que esta anestesia total apanhando todo o membro e dos 2 lados só se encontra na secção completa da medula, enquanto, por outro lado, este tipo de anestesia é frequentemente encontrado em pitiaticos, que a constroe principalmente por uma "simulação inconciente", como parece ter se dado no nosso caso.

Finalmente o exame eletrico demonstra a integridade do neuronio motor periferico, pois ao envez das alterações degenerativas, encontramos hiperexcitabilidade galvanica, em um paciente que estava paraplegico ha meses.

A estaso e basofobia: ficam eliminadas porquanto o quadro histerico está nitidamente manifesto e predominando sobre as manifestaçōes fóbicas: o paciente não tem medo de ficar em pé nem de andar, pois ele até está sempre tentando melhorar sua marcha.

Os pequenos ataques apresentados pelo doente são tăo típicos que nīo comportam diagnostico diferencial com a epilepsia e os equivalentes epilepticos, mesmo porque a constituiçāo pitiatica, o modo como aparecem "como se agravam os disturbios e a disbasia apresentada pelo doente, confirmam pienamente a sua natureza histérica. Quanto à disbasia apresentada pelı paciente, é do tipo da astasia-abasia-puralitica e o film que documenta este trabalho nos mostra com a maior fidelidade possivel os caracteristicos da referida disbasia. Finalmente é necessario nunca esquecer-se o fator "simulaçã 
conciente" e então é-se obrigado a lançar mão de certos tests. No caso em apreço um tipo de simulação foi desde logo eliminado, mesmo porque só haveria desvantagem para o paciente na situação atual em que se encontra no seu serviço; por outro lado os tests foram negativos. Talvez, mais tarde, si houver conveniencia, seja posto em jogo o contingente conciente na simulação, devendo-se por isso ficar de sobreaviso.

\section{EVOLUÇÃO E TRATAMENTO}

Logo que tomamos contacto com o doente, o que se deu algumas semanas após o seu internamento no hospital, iniciamos o tratamento tonico-reconstituinte, psíquico e fisioterapico. Foram feitas injeções de sôro glicosado hipertonico, insulina e estricnina, ao lado de massagens manuais e eletricas diarias; ao mesmo tempo entramos com o contingente psicoterapico ao nosso alcance. Apesar de toda essa terapeutica a deambulação e o estado psiquico continuaram inalterados, embora tivessomos melhorado muito o estado geral e de nutrição e tonificado os musculos. Foi então que tentamos o "método psico-galvanico". Fizemos 2 secções de torpeadeamento, a primeira no $H$. M. e com cerca de 2 horas de duração, e a segunda no Ambulatório de Neurologia da Santa Casa, com 1 hora de duração, sendo que esta última foi feita pelo Dr. C. V. Savoy. Precedendo esta torpillage empreendemos uma piretoterapia com o dmelcos e preparamos psiquicamente o doente. O resultado infelizmente foi quasi nulo por isso que as melhoras obtidas logo em seguida foram pasrageiras, e depois tudo voltou como antes.

Iamos tentar o método de Estanislaus Von Meduna quando o paciente nos deixou.

O interessante a se notar na evolução do caso é que por ocasião do primeiro torpedeamento a anestesia havia desaparecido pois o paciente sentia perfeitamente o contacto do eletrodo e a passagem da corrente, reagindo às correntes mais fracas - esta foi a razão porque empregamos o termo "fugaz" ao falarmos da anestesia total superficial. Outro ponto interessante é justamente a chamada "fase de meditação de Charcot", que o nosso doente apresentou muito nitida. De fato, relembrando a historia da molestia atual, vimos que após o acidente que foi o desencadeante da sindrome, houve cura da paraplegia inicial que reapareceu cerca de 2 meses depois juntamente com os pequenos ataques histéricos. Este periodo de aparente normalidade quasi completa é que constitue a "fase de meditação" observada por Charcot.

\section{DISBASIAS PITIATICAS}

As disbasias constituem uma das mais frequentes perturbaçóes motoras na hísteria. Fazendo um apanhado rápido sobre os transtornos motores pitiaticos, vamos verificar que a caracteristica principral ros mesmos, é que, quasi sempre todo um membro ou doi: membros são afetados, ao envez de apenas grupos musculares. Com relativa frequencia vamos encontrar entre os transurrnos motores as paralisias ou paresias de um ou mais membro, 
constituindo as monoplegias, formas estas frequentemente apresentadas na hísteria traumática; as paraplegias sobretudo crurais; as hemiplegias em que os doentes nos mostram a clássica "marcha de Todd", isto é, no andar arrastam o pé no chão pela face dorsal dos artelhos e sem aquele movimento ceifante dos hemiplegicos organicos; os franceses chamam-na de "marcha en draguant" (rastejante). Nem todos os neurologistas acreditam na hemiplegia hísterica, e Rimbaud afirma nunca ter visto qualquer caso de hemiplegia dessa origem. As paralisas hítericas para o lado dos territorios dependentes de nervos craneanos também não são raras.

As contraturas constituem outros transtornos motores da hísteriạ e surgem em condições identicas às das paralisias. Assim é que existem as contraturas dos dedos formando garras, do ante-braço sobre o braço, da perna sobre a coxa, do pé trazendo o equinismo, etc. Os espasmos são comuns, sobretudo os esofagianos e que os doentes comparam com uma bola que sobe pela garganta; há também os espasmos em outros pontos como os vaginais, pilóricos, etc.

Finalmente chegamos ao grupo das astasiag-abasias e que mais nos interessam dentre as disbasias hístericas. A astasia-abasia vem a ser a impotencia motora dos membros inferiores quando o individuo tenta ficar em pé ou andar.' Pode ser uma astasia-abasia relativa, isto é, o paciente não está de todo impossibilitado de ficar em pé e andar, ou pode ser absoluta e então o paciente não consegue nem ficar em pé. No primeiro caso a estação ereta é mantida com dificuldade, por isso que o histerico alarga muito sua base de sustentação; si tenta andar, só o consegue por meio de passos hesitantes, incertos, parecendo uma creança que se está iniciando na marcha esta forma é chamáda parética ou paralitica; outras vezes, quando o paciente começa a andar, seus membros executam movimentos irregulares de flexão e extensão, desordenados, involuntários, com ocilações do tronco e da cabeça para frente e para tráz - eis então a forma coreica; por vezes os membros inferiores se enrijecem e apresentam uma especie de trepidação, lembrando mais ou menos as marchas espasticas - é a astasia-abasia trepidante; esta trepidação pode ser tão acentuada que o individuo anda aos saltos e teremos assim, finalmente, a forma saltatoria ou saltitante da astasia-abasia. Outras modalidades existem da astasia-abasia, como a oscilante de Sumont e Brunelle, a astasia por crises de Sodame, e as astasiasabasias dos psiconeuróticos; dentre estas últimas temos 3 formas principais: a basofolia em que o doente tem medo de andar; a estasofobia em que o doente tem medo da posição em pé. e finalmente a agorafobia cm que o paciente tem medo de andar em certos lugares. Aloysio de Castro ainda cita a 'astasia-abusia selal. e the dá um substratum anatomico (lesões escleróses arteriais cerebraic), por isso que aparece em relhos sem estigmas neuropaticos: é lk inicio lento e evolução muito prolongada. Walcla cita a - attasiaabasia após trauma craneano. 
Finalmente, não podemos deixar de citar as astasia-abasias cerebelares.

\section{CLINICA}

A astasia-abasia hiterica aparece em qualquer idade e sexo, e geralmente após uma emoçã oforte ou um choque físico, em individuos neuropáticos ou nitidamente hístericos. Pode apresentar-se sob qualquer daquelas formas já descritas e tem uma duração variavel, dependendo do doente e da terapeutica. A terminação muitas vezes se faz como no inicio, isto é, bruscamente.

\section{DIAGNOSTICO DIFERENCIAL}

E' preciso separar a astasia-abasia híterica das dos neurastenicos, por isso que nestes últimos o fator "medo" é o dominante. Outra disbasia a ser separada é a paraplegia cruràl híterica ou não; quando é orgânica encontramos logo os sinais e sintomas caracteristicos das lesões orgânicas nervósas sejam centrais sejam periféricas; naparaplegia hísterica o individuo mesmo deitado não consegue movimentar seus membros suficiêntemente. As ataxias serão logo eliminádas pela verificação das incoordenações, disturbios da sensibilidade profunda, marcha, etc. $E^{\prime}$ preciso nunca esquecer o fator "simulação conciente" e para isso lança-se mão de determinádos tests variaveis consoante o caso. Um dos tests é o seguinte: si o individuo diz que não pode parar em pé ou simula equilibrio instavel nessa estação, nós mandamos que êle se encoste numa parede onde naturalmente se apoiará para não cair ou ocilar; em seguida mandamos que êle feche os olhos e tentamos desviar sua atenção obrigandoo executar certos movimentos com os quais procuramos afastá-lo da parede: nesse movimento observamos então, que o simulador, muitas vezes deixa o apoio e apresenta-se, pelo menos alguns segundos, num equilibrio perfeitamente normal sem dar pelo fato. Esse test também pode ser usado para os casos de simulação de ataxia, sobretudo do Romberg em individuo previamente instruido.

\section{DIAGNOSTICO}

Baseia-se principalmente no resultado absolutamente negativo do exame neurológico e dos exames complementares (reflexos todos normais, ausencia de sinais e sintomas de libertação ou de sindrome deficitária piramidal, esfincteres normais, ausencia de disturbios tróficos acentuados, líquido céfalo-raquidiano normal, exame eletrico negativr, etc.) ; à essa negatividade do exame neurológico e dos exames complementares, acrescente-se a presença de disturbios sensitivos de 
tipo histerico (anestesias em manguito ou em luvas, variabilidade dos disturbios sensitivos consoante a época do exame ou o segmento examinado) e mais, por vezes a sindrome hísterica.

Finalmente há a parte terapeutica em que pela persuação consegue-se remover os disturbios, porquanto sabemos que pelo conceito de Babinski a híteria gira em torno da sugestão.

Prognosticos Bom, pois nos casos em que ainda não houve a cristalisação a cura geralmente é muito rapida.

\section{TRATAMENTO}

O tratamento das astasia-abasias como de todos os transtornos motores da hísteria, maximé nas formas paraliticas, tomou novo rumo após os trabalhos de Clovis Vincent durante a guerra de 1914-1918. Este autor enriqueceu a terapeutica neurologica com mais um poderoso elemento de combate às neuroses pitiaticas, elemento esse representado pela "Psico-terapia-armada" Mesmo nos transtornos puramente sensitivos da hísteria esta terapeutica tem sido usada com sucesso. Sobre ela nada precisaremos descrever tão conhecida e empregada é na moderna neurologia. Ao lado da psicoterapia armada, precendendo-a mesmo, são muito uteis a "pirtetorapia" e a "terapeutica de choque" Uma das mais modernas terapeuticas de choque é a representada pelo processo de Von Meduna, isto é, a "convulsoterapia" pelo cardiazol e em que se empregam o cardiazol em sol. a $10 \% 3$ a $5 \mathrm{cc}$. bruscamente na veia. A convulsoteriapia só deverá ser usada após terem falhados os outros recursos de que se puder dispôr. Sobre o método de Von Meduna a literatura já está muito enriquecida de modo que seria fastioso estuda-lo aqui novamente. Finalmente a "psico-analise" constitue outro recurso, aliás, de grande valia, no tratamento das astasia-abasias e outros disturbios histericos.

E' sempre util combinar varios destes processo terapeuticos afastando o doente do ambiente familiar e acalmando-o com banhos mornos prolongados, sedativos e hipnóticos brandos.

\section{ETIOPATOGENIA}

De acordo com o que já descrevemos em linhas anteriores, do ponto de vista etiopatogenico podemos separar as asta-abasias em 2 grupos: aquelas resultantes de disturbios puramente funcionais, e as que dependem de lesões organicas. As primeiras representam a maioria dos casos, e são sobretudo manifestaçōes da sindrome histerica e muito menos vezes da neurastenia. Que as astasia-abasias constituem frequentemente manifestaçōes hístericas confirmam quasi todos os autores. Foi Charcot quem primeiro mostron a relaça 
entre estas disbasias e a hísteria. Juntamente com Blocq procurou explica-las como sendo consequencia da falta de ação dos centros "secundarios medulares" sob cujos influxos estaria dependente a coordenação dos movimentos automaticos. Assim sendo, consideram a marcha um "ato automatico secundario" dependente desses centros medulares. Faltando a ação dos centros medulares haveria como resultado a astasia-abasia. Ballet acha que estas disbasias dependeriam da amnésia dos movimentos indispensaveis à estação vertical e à marcha. Sendo assim, a patogenia destas avança pelos terrenos ainda não bem conhecidos da hísteria, terrenos esses onde germinam exuberantemente as hipoteses e teorias. Assim sendo não é de nossa intenção entrarmos em considerações sobre essa patogenia já muito discutida. Considerando agora as astasia-abasias de certos psiconeuróticos verificamos que aí o que predomina é o fator "medo" conforme já descrevemos arteriormente. Finalmente, batendo na tecla organica, vamos verificar a existencia de "astasia-abasias organicas". frequentemente por lesões do paleocerebelo. De fáto; o vermis é o cerebelo postural ou estático e dos movimentos automáticos, enquanto o neocerebelo é o cerebelo dos movimentos voluntarios. A astasia-abasia paleocebelosa se caracterisa pelo alargamento da base de sustentação na estação vertical, oscilações do corpo em todos os sentidos, marcha titubeante com balanceamento do tronco; o fechamento dos olhos não acentúa os disturbios; evidentemente que não ha Romberg. O paleocerebelo pela sua relação espinhal atravez a "via cerebelo-rubro espinhal" regula, por um mecanismo predom nante inhibidor, os reflexos proprioceptivos isto é, que se geram no proprio orgão, e o tonus muscular consoante as necessidades da "posição en pé" De fáto, é sabido que o individuo para se manter em pé tem todos os seus musculos num certo estado de tonus necessario para a permanencia do corpo naquela posição - é o que se chama "tonus de atitude". Mesmo numa imobilidade aparentemente absoluta, o individuo executa pequenas oscilações; assim, experiencias feitas na Alemanha com individuos de há muito habituados ao serviço militar mostraram essas oscilações: colocando-se sobre suas cabeças capacetes com um dispositivo capaz de riscar um papel, e ordenando-lhes imobilidade completa na posição de "sentido militar", notava-se que o papel éra riscado. mostrando apenas oscilações conforme o grau de treinamento do individuo.

Compreende-se que, si essas oscilações se dão normalmente e $\mathrm{em}$ individuos treinados, as lesões do vermis deverão trazer oscilaçōes muito amplas até mesmo a astasia por vezes completa. Pela relaçào re-tibular o paleocerebelo regula o funcionamento tonico e fasico do aparelho neuro-muscular do qual depende o equilibrio aéreo e aquatico.

Com este breve apanhado da fisiopatologia do paleocerebelo compreende-se como as lesines deste possam acarretar astasia-abasias. 
Aluizio de Castro cita, em sua Semiologia, a "astasia-abasia senil", por arterio-esclerose cerebral.

Finalmente Wald considera as astasia-abasias após trauma craneano.

Estas últimas não seriam manifestações hítericas em que o trauma apenas atuou como causa desencadeadora? - Não seriam em suma "Sindromes Psico-organicas"?

\section{BIBLIOGRAFIA}

Vampré, E. - Perturbąões pitiaticas - Ann. Pant. Med. Cir. 5 (12) 110-111 dez. 1907.

VAmprE, E. - Histeria masculina - Arch. Soc. Med. Cir. S. Paulo 1 (6) 314-322. Nov. de 1910.

Austregesildo, A. - Șobre um caso de simulação histerica - Rev. Med. S. Paulo 5 (1) 21-22. Jan. de 1902.

LAGRANGE, B. - Rapport sur un degéneré heréditaire aceusé de fantex et atteint d'hystérie et d'astasie-abasie - Congrés Annuel de Medicine Mentale - pag. 481, de 1893.

Longo P. W. e BAstos, F O. - Dois casos de amauróse total pitiatica curados pelo método psico-galvanico - Revista da Associação Paulista de Medicina, vol. XII n.o 3, março de 1938, pgs. 187-194.

Estrada, H. D. - Astasia-abasia. Sobre um caso de astasia-abasia trcpidante - Gaz. Clin. S. Paulo 3 (4) 137-146, abril de 1905.

VeIgA, H. D. - Um caso de astasia-abasa - Gaz. Clin. S. Paulo. 20 (7) 99-100, julho de 1922 e 20 (8) 119-120 de agosto de 1922.

BAUER - Pratique médico-chirurgicale - vol. I.

Wald-Ein Fali von - Astasia Abasia Nach Schädelverletzung in Deutsch - Med. Woch 1897 B 482.

Dejerine - Sémiologie des affections des système nervecu.x - Astasie-abasie pag. 442 e Paraplegie histerique pags. 313-315.

Castro Aloysio De - Semiótica nervosa - Semiótica das disbasias pag. 117-171.

Curschmann-Kramer - Tratado de las enfermidades del sistema nervioso 1932 - Transtornos motores da histeria pag: 742.

Litter e Wexselblatt - Tratado de Neurologia 1939 - Paraplegias funcionais pag. 147.

Rrmbaud - Compendio de Neurologia - pags. 443 e 930.

Roger BINET - Traité de Physiologie normale et pathologique. Fasc. I 1935 - pags. 39-1934. 